\title{
Púrpura em paciente com estrongiloidíase disseminada
}

\author{
Purpura in patient with disseminated strongiloidiasis
}

\author{
Luciano C. Ribeiro ${ }^{1,2}$, Edson N.A. Rodrigues Junior'2, Margareth D. Silva², \\ Arley Takiuchi ${ }^{2}$ e Cor Jesus F. Fontes ${ }^{1,2}$
}

\begin{abstract}
RESUM0
Ainfecção pelo Strongyloides stercoralis em associação com imunosupressão pode manifestar-se com lesões em múltiplos órgãos e sistemas, caracterizando a forma disseminada da doença. Lesões cutâneas não são freqüentemente relatadas e, se presentes, manifestam-se como rash e petéquias. Púrpuras bem definidas são pouco descritas. № presente trabalho é descrito um caso de estrongiloidíase disseminada, com acometimento cutâneo em forma de púrpura, que se desenvolveu em um paciente timectomizado e usuário crônico de corticosteróide devido à miastenia gravis.
\end{abstract}

Palavras-chaves: Estrongiloidíase disseminada. Púrpura.

\begin{abstract}
The association of systemic corticosteroid therapy and dissemination of Strongyloides stercoralis has been increasingly documented in the literature. Skin involvement in disseminated strongyloidiasis has been reported and the most commonly described cutaneous manifestations are rash and petechial eruptions. We present a case of an immunosuppressed man that developed disseminated strongyloidiasis with extensive purpura.
\end{abstract}

Key-words: Disseminated strongyloidiasis. Purpura.

A estrongiloidíase é uma helmintose predominantemente intestinal, causada pelo Strongyloides stercoralis, sendo o homem seu principal reservatório, e a principal fonte de infecção. 0 risco de infecção é diretamente proporcional às condições de higiene do indivíduo. Apresenta ampla distribuição mundial, porém, com maior prevalência nas regiões tropicais e subtropicais. No Brasil, os dados variam de acordo com a região, com prevalência variando de 15 a 82\%, mantendo uma média de 20\%9.

0 Strongyloides stercoralis possui dois tipos de ciclo evolutivo: o direto ou homogônico e 0 indireto ou heterogônico, sendo que no homem ocorre ainda a auto-infecção, que pode ser de forma interna ou externa. Em situações especiais, o ciclo de auto-infecção pode acelerar-se, levando à rápida elevação do número de vermes nos órgãos normalmente envolvidos no ciclo biológico, fenômeno conhecido como hiperinfecção. Pode evoluir para estrongiloidíase disseminada, que se estabelece quando ocorre uma aceleração do curso normal do ciclo biológico do parasita e invasão, pelas larvas filariformes, de órgãos como pele, sistema nervoso central, rins, fígado, com alta mortalidade ${ }^{6}$. Esta complicação ocorre com maior frequêencia em indivíduos com depressão da imunidade celular por neoplasias (linfomas, leucemias), transplantados renais, alcoólatras e infecção pelo vírus da imunodeficiência adquirida humana (HIV) ${ }^{10}$.

No presente trabalho, é descrito um caso de estrongiloidíase disseminada, com acometimento cutâneo em forma de púrpura, que se desenvolveu em um paciente timectomizado e usuário crônico de corticosteróide devido à miastenia gravis.

\section{RELATO DE CASO}

JJ, masculino, 36anos, portador de miastenia gravis diagnosticada há cinco anos. Realizou timectomia há três anos, após a qual passou fazer uso de piridostigmina e prednisona (60mg/dia). Admitido no Hospital Universitário Júlio Muller, em 7 de outubro de 2002, com quadro de vômitos e diarréia aquosa esverdeada, sem muco, pus ou sangue, de 20 dias de evolução. Apresentava ainda febre intermitente não aferida, inapetência, cólicas abdominais difusas de forte intensidade, tosse produtiva

1. Núcleo de Estudos de Doenças Infecciosas e Tropicais de Mato Grosso, Cuiabá, MT. 2. Departamento de Clínica Médica da Faculdade de Ciências Médicas da Universidade Federal de Mato Grosso, Cuiabá, MT.

Endereço para correspondência: Dr. Luciano Corrêa Ribeiro. Rua C nº 63, Jardim Ubatan, 78010-670 Cuiabá, MT.

e-mail: lucorrea@terra.com.br

Recebido em 13/9/2004

Aceito em 2/3/2005 
com expectoração esbranquiçada, astenia e emagrecimento de cerca de $5 \mathrm{~kg}$ no período.

Ao exame físico, apresentou-se em regular estado geral, apático, hipocorado, desidratado, emagrecido, eupnéico, anictérico, afebril, com diminuição difusa e moderada da força muscular. Os exames complementares revelaram hiponatremia (114meq/L) , leve granulocitose ( 8.200 células $/ \mathrm{mm}^{3}$ ), ausência de eosinófilos, anemia normocrômica e normocítica (Hb 11,2g/dL), plaquetas de $216.000 / \mathrm{mm}^{3}$, hematúria importante e raio-X de tórax normal. Pesquisa de anticorpos anti-HIV resultou negativa.

Dois dias após a internação o paciente apresentou febre baixa $\left(38^{\circ} \mathrm{C}\right)$, dispnéia e hemoptise. Surgiram-lhe lesões cutâneas pápulo-eritematosas e purpúricas em membros superiores, região proximal dos membros inferiores e abdome (Figura 1). Evoluiu com sinais de irritação peritoneal e surgimento de infiltrado pulmonar retículo-nodular difuso bilateral ao raio-X. Os exames laboratoriais desse dia revelaram queda dos níveis da hemoglobina $(7,2 \mathrm{~g} / \mathrm{dl})$ eda contagem deplaquetas $\left(174.000 / \mathrm{mm}^{3}\right)$, com aumento dos granulócitos ( 10.200 células $/ \mathrm{mm}^{3}$ ). Observouse baixa atividade de protrombina (32,9\%) e hipofibrinogenemia (120mg/dL) , além de hiperbilirrubinemia indireta (1,36mg/dL) e níveis de $\mathrm{LDH}$ de $808 \mathrm{u} / \mathrm{L}$.

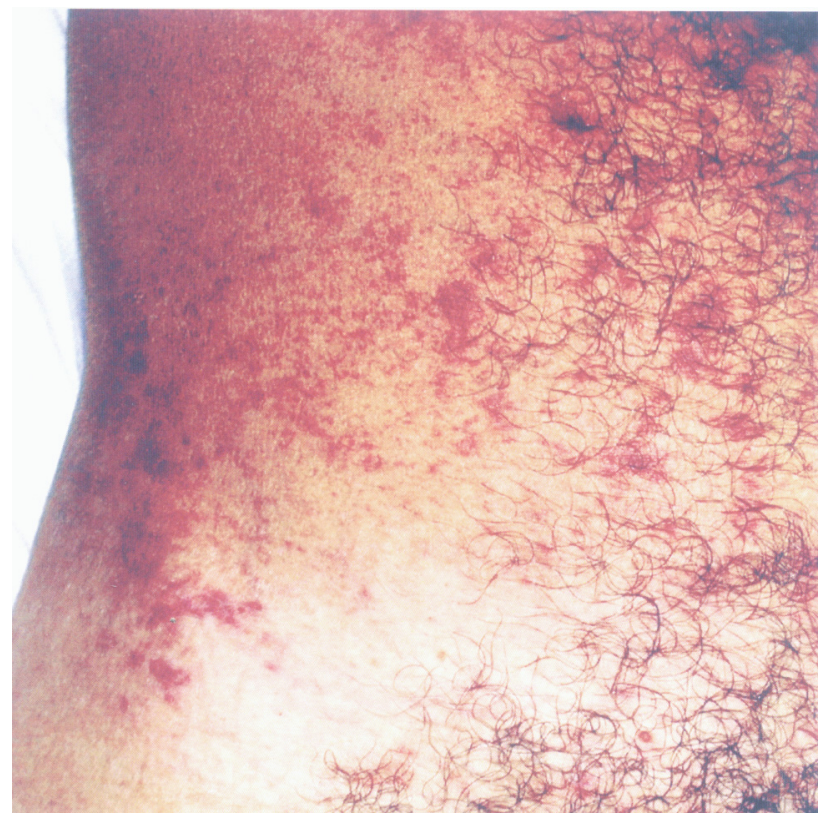

Figura 1 - Lesões purpúricas abdominais apresentadas pelo paciente no segundo dia de internação.

Pela alta probabilidade de etiologia infecciosa para 0 quadro, iniciou-se antibioticoterapia de largo espectro, com cefalosporina de quarta geração e imidazólico, após coleta de material biológico para exames, sendo constatada grande quantidade de larvas de S. stercoralis no exame direto de escarro e fezes. 0 exame histopatológico das lesões purpúricas da pele revelou discreto infiltrado linfocitário perivascular superficial com presença de fragmento de larva do helminto em meio às fibras do colágeno dérmico (Figura 2). A investigação de bactérias e fungos no escarro, fezes, urina e sangue foi negativa. Iniciada terapêutica com tiabendazol na dose de $25 \mathrm{mg} / \mathrm{kg} / \mathrm{dia}$,

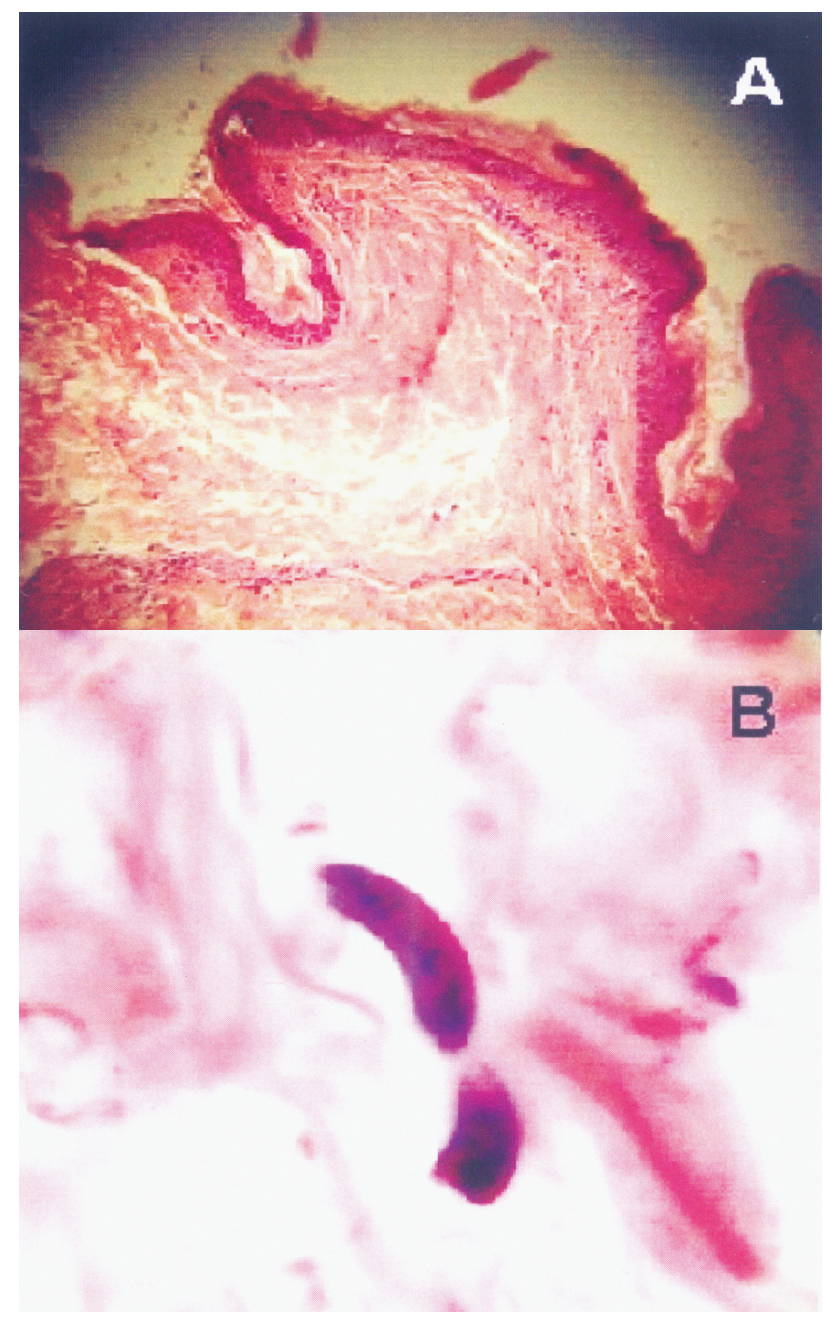

Figura 2 - Aspecto histopatológico da lesão cutânea purpúrica apresentada pelo paciente, mostrando: A) discreto infiltrado inflamatório; B) fragmento de larva do Strongyloides stercoralis em meio às fibras do colágeno dérmico.

por 10 dias, com melhora progressiva do quadro. Recebeu alta hospitalar no 8 dia de internação, prosseguindo 0 tratamento em nível ambulatorial, sem intercorrência.

\section{DISCUSSÃ0}

A doença causada pelo S. stercoralis no homem pode manifestar-se em três formas clínicas: aguda, crônica (não complicada ou complicada) e disseminada. A forma clínica inicial da infecção aguda é pouco relatada na literatura e pouco notificada pelo médico. Na forma crônica não complicada os sintomas gastrintestinais são os mais relevantes, enquanto que na forma complicada o paciente geralmente apresenta sintomas respiratórios como broncoespasmo e síndrome de angústia respiratória do adulto, podendo associar-se à pneumonia bacteriana secundária ${ }^{512}$. Em associação com imunosupressão, 0 espectro clínico tende a se agravar, ocorrendo manifestações de lesões em múltiplos órgãos e sistemas, caracterizando a forma disseminada da infecçã $0^{1}$.

0 paciente ora relatado fazia uso de corticosteróide, sendo este 0 provável fator desencadeante da disseminação do S. stercoralis. 
De fato, em casos graves de estrongiloidíase, é consenso que 0 principal fator predisponente para a apresentação sistêmica da parasitose é a imunossupressão, sendo o uso crônico de corticosteróide imputado, quase que em unanimidade, como 0 mais importante fator de risco?

A manifestação cutânea mais comum na estrongiloidíase é a larva currens, isto é, lesão urticariforme, linear, pruriginosa, normalmente única e ocasionalmente múltipla, decorrente da penetração ativa da larva na pele da borda anal do indivíduo ${ }^{8}$. As lesões de pele na forma disseminada resultam da disseminação hematogênica do parasita, conforme já descrito em lesões do parênquima cerebral, com características isquêmicas, consequientes à embolização do nematóde $0^{6}$. Outra explicação seria a migração das larvas através da parede dos vasos sangǘneos na derme papilar, causando hemorragia petequial. Além disso, as larvas podem também migrar a partir da cavidade peritoneal, após terem invadido os vasos da parede do intestino delgad $0^{4,2}$. Independente do mecanismo, lesões cutâneas não são freqüentemente relatadas e, se presentes, manifestam-se como rash e petéquias. Púrpuras bem definidas, tal como as apresentadas pelo paciente, são pouco descritas ${ }^{811}$.

A eosinofilia comumente encontrada em algumas parasitoses intestinais, inclusive na estrongiloidíase, mostra tendência a ser menos (20\%) freqüente na forma disseminada da doença, à medida que a infecção se agrava. Embora esta redução possa ser efeito da corticoterapia sobre os eosinófilos, a ausência de eosinofilia também foi relatada em indivíduos com outras causas de imunossupressão que não 0 uso de corticosteróides, ao desenvolverem infecção disseminada ${ }^{4}$. De modo geral, a eosinopenia implica mau prognóstico, o que se confirmou na apresentação da gravidade inicial do paciente, que não apresentava eosinófilos no sangue periféric ${ }^{3}$.

Um grande complicador da estrongiloidíase disseminada consiste na infecção secundária, como pneumonia, meningite, endocardite e sepse, sobretudo por enterobactérias ou eventualmente fungos, podendo mascarar a infecção pelo $\mathrm{S}$. stercoralis. Isto ocorre devido à ruptura da barreira intestinal pela penetração do parasita, associada à diminuição da motilidade do trato digestivo, que ocorre associada à hiperinfecção ${ }^{4}$. No caso aqui referido, 0 início precoce da antibioticoterapia de largo espectro, na vigência da suspeita inicial de processo infeccioso inespecífico grave, possibilitou melhor prognóstico do paciente, evitando a evolução para as complicações acima citadas.

É bem provável que 0 tratamento empírico periódico desta parasitose seja benéfico em pacientes de alto risco, sobretudo os usuários crônicos de corticóides sistêmicos.

\section{REFERÊNCIAS BIBLIOGRÁFICAS}

1. Archer T, Mazzaferri E. Rash and shortness of breath in an elderly woman. Hospital Practice 33:89-92, 1998.

2. Coulter C, Walker DG, Gunsberg M, Brown IG, Bligh JF, Prociv P. Successful treatment of disseminated Strongyloides. Medical Journal of Australia 157:331-333, 1992.

3. Feltz MVD, Slee PHThJ, Hees PAM, Tersmette M. Strongyloides stercoralis infection: how to diagnose best? The Netherlands Journal of Medicine 55:128-131, 1999.

4. Ghoshal UC, Ghoshal U, Jain M, Kuman A, Aggarwal R, Misra A, Ayyagari A, Naik S. Strongyloides Stercoralis infestation associated with septicemia due to intestinal transmural migration. Journal of Gastroenterology and Hepatology 17:1331, 2002.

5. Grove DI. Clinical manifestations. In: Grove DI (ed) Strongyloidiasis: a major roundworm infection of man. Taylor and Francis, Philadelphia, p. $155-173,1989$.

6. Kothbary NN, Muskie JM, Matbur SC. Strongyloides stercoralis hyperinfection. Residents' teaching files 19:1077-1081, 1999.

7. Lemos LB, Qu Z, Laucirica R, Fred HL. Hyperinfection syndrome in strongyloidiasis: report of two cases. Annals of Diagnostic Pathology 7:87-94, 2003.

8. Ly MN, Bethel SL, Usmani AS, Lambert DR. Cutaneous Strongyloides stercoralis infection: an unusual presentation. American Academic of Dermatology 49:157-160, 2003.

9. Machado ER, Costa-Cruz JM. Strongyloides stercoralis and other enteroparasites in children at Uberlandia city, state of Minas Gerais, Brazil. Memórias do Instituto Oswaldo Cruz 93:161-164, 1998.

10. Porto MAF, Muniz A, Oliveira-Jr J, Carvalho EM. Implicações clínicas e imunológicas da associação entre 0 HTLV I e a estrongiloidíase. Revista da Sociedade Brasileira de Medicina Tropical 35:641-649, 2002.

11. Reddy T. Syndrome of inappropriate secretion of antidiuretic hormone and nonpalpable purpura in a woman with Strongyloides stercoralis hyperinfection. American Journal of the Medicine Sciences 2355:288-291, 2003.

12. Scowden EB, Schaffner W, Stone WJ. Overwhelming strongyloidiasis: an unappreciated opportunistic infection. Medicine 57:527-544, 1978. 